\title{
Dos ciudades por el agua y contra el agua, Santiago (Chile) y Murcia (España): patrimonio a partir del río como elemento de fundación y destrucción
}

Two cities by water and against water, Santiago (Chile) and Murcia (Spain): heritage from the river as an element of foundation and destruction

Historial del artículo

Recibido:

13 de abril de 2020

Revisado

27 de mayo de 2020

Aceptado:

08 de junio de 2020

\section{Gregorio Castejón Porcel ${ }^{\mathrm{a}}$}

a Departamento de Geografía Humana de la Universidad de Alicante, Alicante, España. Correo electrónico: gregorio. castejon@ua.es

Palabras clave

Murcia, patrimonio, río

Santiago de Chile

\section{Keywords}

Heritage, Murcia, river, Santiago de Chile

\begin{abstract}
Resumen
Las ciudades de Santiago y Murcia, a pesar de las diferencias históricas en su génesis y evolución, poseen una condición identitaria que las convierte en emplazamientos cuya existencia está marcada por un mismo elemento geográfico, el río. Tal y como se expone en este trabajo, fundamentado en un estudio comparado en base al análisis bibliográfico, documental y el trabajo de campo, en ambos casos, los caudales de estas corrientes servían para irrigar un espacio de huerta que garantizó el desarrollo de las urbes; además, de igual forma, ambas han sobrevivido defendiéndose frente a las arroyadas mediante la construcción de sendas infraestructuras de encauzamiento. En consecuencia, las obras de domesticación para el uso agrícola e industrial de las aguas, así como las labores de defensa, dieron lugar a un patrimonio de enorme valor y relevancia, cuya salvaguarda y promoción se demuestra que necesita de una mayor consideración, protección e impulso turístico cultural.
\end{abstract}

\section{Abstract}

The cities of Santiago and Murcia, despite the historical differences in their genesis and evolution, have an identity condition that makes them sites whose existence is marked by the same geographical element, the river. As it is exposed in this work, based on a comparative study based on a bibliographic and documentary analysis and field work, in both cases the flows of these streams served to irrigate a cultivation space that guaranteed the development of the cities; and, in addition, in the same way, both cities have survived defending themselves against the flash floods by means of the construction of the similar channeling infrastructures. Consequently, the domestication works for the agricultural and industrial use of the waters as well as the defense works, gave rise to a heritage of enormous value and relevance, whose safeguarding and promotion is shown to require greater consideration, protection and cultural and tourist promotion. 


\section{Introducción}

El agua es un elemento que transforma el paisaje natural de dos maneras: como agente modelador, mediante la erosión y el transporte de sedimentos, y a modo de componente vivificador, posibilitando la irrupción de vida en aquellos lugares donde hace acto de presencia, como ocurrió en las ciudades de Santiago y Murcia (Martí \& Moreno, 2010; Puertas, Henríquez \& Meza, 2014). No obstante, también es un sujeto transformador del paisaje antropizado, ya que la forma en que el ser humano ha hecho uso de ella y se ha defendido de su exceso, ha dado lugar a manifestaciones y obras que han moldeado la imagen de las áreas ocupadas y explotadas por este. Así, su importancia vital motivó la edificación de construcciones de distinta envergadura diseñadas para lograr los objetivos propuestos por los integrantes de las múltiples sociedades que conviven en la Tierra, acciones con las que se demuestra el ingenio y la necesidad de domesticar este preciado recurso natural, hoy en peligro en las ciudades de estudio debido al gran incremento de la demanda y a las variaciones climáticas (Grindlay, Zamorano, Rodríguez \& Molero, 2009; Senent, Pérez, Carrillo \& Soto, 2017; Valdés et al., 2014).

Estas obras, por su relevancia cultural, histórica y arquitectónica, constituyen un auténtico elenco patrimonial de gran valor, que, en este caso, se originó por la referida dicotomía del aprovechamiento del río y la lucha contra el mismo; cauces integrados en el paisaje urbano desde el siglo XVIII como recursos lúdico-paisajísticos y, más recientemente, ambientales (Figueroa, 2009, 2012; Martínez, Pellicer \& Colino, 2014; Vásquez, 2016).

De esta forma, el primer objetivo del presente estudio comparado es poner de manifiesto las similitudes y la enorme importancia de este patrimonio hidráulico generado en torno al uso y defensa de las aguas de dos ríos con idénticas capacidades de producción y destrucción, cursos ubicados en dos enclaves del mundo separados por el océano Atlántico, Santiago (Chile), con el río Mapocho, y Murcia (España), con el río Segura. Dos ciudades con una evolución histórica, demográfica y urbana distinta, pero en las que, a razón de los resultados obtenidos, la respuesta para salvaguardar la supervivencia de sus habitantes fue la misma, la doma de unos cursos fluviales cuyos caudales eran, a partes iguales, símbolo de vida y sinónimo de muerte, lo que dio lugar en ambos casos a una extensa red hidráulica e industrial y a una imponente y sólida construcción defensiva.

En segundo lugar, el siguiente propósito es examinar el grado y modo en el que estos elementos patrimoniales, tanto tangibles como intangibles, asociados al río y ligados a ambos asentamientos, están protegidos por la legislación vigente en cada territorio y qué figuras de conservación poseen; así como también la manera en que se hace uso de estos como recursos culturales y turísticos. Un examen que aporta grandes contrastes, tanto en lo que se refiere al criterio de protección, más generalizado en el marco chileno, pero con la pervivencia de menos recursos, como en el de divulgación, mucho más importante en el ámbito murciano, con un significativo número de centros expositivos que dedican parte de su discurso al legado hidráulico.

De acuerdo con lo indicado, el trabajo se divide en tres apartados: 1. Una introducción al estudio. 2. El análisis de resultados, donde se expresan: a) Una presentación geohistórica de las ciudades de análisis, b) las similitudes en lo que a obra hidráulica de aprovechamiento del agua se refiere, c) los resultados del estudio de las concordancias respecto a la obra defensiva, d) el modo en el que este patrimonio ha sido protegido legalmente por las administraciones públicas, y e) el examen de la forma en que dicho patrimonio se utiliza culturalmente. Y, por último, 3. La discusión de los resultados obtenidos en el contexto del estado del asunto.

Por otro lado, en lo que respecta a los antecedentes, no se conoce de ningún estudio que aborde un análisis comparativo de las características del presente trabajo, por lo tanto, se trata de una investigación totalmente novedosa. No obstante, en el caso de la capital de Chile, Castejón (2019) publicó, recientemente, un estudio en el que se analiza, a nivel nacional, la consideración cultural y turística del patrimonio hidráulico de este país. Para el caso de Murcia, en Castejón \& Canales (2016) se defendió la necesidad de la creación de un «Memorial del Agua» en la ciudad como centro expositivo regional de los importantes elementos asociados a la Cultura del Agua en la Comunidad Autónoma.

En lo referente a Santiago, se sabe de diversas publicaciones que citan la existencia e importancia de las canalizaciones hidráulicas (Astaburuaga, 2004; Figueroa, 2007, 2009, 2012 y 2013; Hidalgo \& Vila, 2015; Rosas \& Pérez, 2013; Sahady, Bravo, Quilodrán \& Szmulewicz, 2014), los antiguos molinos de la ciudad (Sahady et al., 2014) o las obras del Tajamar (Figueroa, 2009; Guajardo, 2018). Sin embargo, apenas se analiza su valor patrimonial como recurso turístico, aunque sí se le da importancia a nivel cultural. Por el contrario, para Murcia existe un vasto compendio de publicaciones referidas al examen del patrimonio hidráulico histórico de esta urbe, tanto en lo 
que se refiere a las edificaciones ligadas a su huerta como a la obra defensiva del Malecón; suma de trabajos que hace difícil una selección, pero que ponen de manifiesto, sin duda, el atractivo cultural de estos elementos, sin embargo, vagamente subrayan su valía como recurso turístico.

\section{Materiales y Métodos}

Las fuentes utilizadas se corresponden con: la bibliografía afín al objeto de estudio identificada en distintos repositorios científicos en línea, además de aquellas aportaciones publicadas en las revistas de las distintas universidades presentes tanto en Santiago como en Murcia, así como en las de otros centros educativos o entidades dedicadas a la divulgación académica; el material documental referente a las construcciones hidráulicas a examen y la documentación cartográfica histórica custodiada en el Archivo General de la Región de Murcia (AGRM), el Archivo Municipal de Murcia (AMM), el Archivo General Militar de Madrid (AGM) y la Biblioteca Virtual de Patrimonio Bibliográfico (BVPB) para el caso de Murcia y en el de Santiago en el Archivo Nacional Histórico de Chile (AHN); la normativa y legislación vigente en materia de patrimonio aprobada y publicada por los organismos competentes, tanto a nivel regional como estatal: Gobierno de España, Comunidad Autónoma de la Región de Murcia y Gobierno de Chile; y, por último, los propios centros expositivos o museos existentes en las dos urbes identificados en el apartado correspondiente.

El método empleado se corresponde con un estudio comparado entre ambas metrópolis. En primer lugar, con base en la revisión bibliográfica de aquellos artículos y libros específicos sobre la temática o que aportan información de interés para el análisis y la consulta de documentación cartográfica histórica y arquitectónica custodiada en los archivos consultados, se ha realizado una búsqueda de similitudes ligadas al uso de los caudales de las corrientes fluviales que atraviesan las ciudades y la forma en que su población se defendió y defiende frente al ímpetu de las aguas en situaciones de crecida. A continuación, se ha indagado en las distintas figuras de protección del patrimonio hidráulico asociado a estas obras mediante el análisis jurídico de las legislaciones vigentes en materia de protección patrimonial, así como se han consultado los boletines oficiales en los que se publican las resoluciones a las solicitudes de designación de figuras de protección, en el caso de Murcia el Boletín Oficial de la Región de Murcia (BORM). Por último, mediante la visita presencial a los museos existentes tanto en Santiago como en Murcia y la revisión de los portales de Internet de estos centros expositivos, se ha elaborado una evaluación de la forma en que esta riqueza cultural material o inmaterial se tiene en consideración turística y culturalmente en ambos enclaves.

\section{Resultados}

\section{Ciudades históricamente subordinadas al agua}

El marco de análisis queda encuadrado dentro del contexto urbano original de las ciudades de Santiago y Murcia, ampliado este al área circundante de ambas asociada directamente a ellas bien mediante el espacio tradicional de huerta inmediato o por medio de los barrios derivados de su crecimiento inicial.

La primera urbe la fundó el gobernador español Pedro de Valdivia en el año 1541 por orden del rey Carlos I de España, mientras que la segunda se constituyó oficialmente como tal en el 825 por Abderramán II, emir musulmán del Califato de Córdoba. No obstante, tanto una como otra se implantaron sobre asentamientos precedentes. En el primer caso, sobre imponiéndose al primitivo caserío indígena, cuya población fue desplazada por medio de las armas tras la Batalla del río Mapocho acaecida en ese mismo año. En el segundo, parece ser que en un lugar colonizado previamente por pobladores romanos. Con todo, orígenes que condicionarían la propia evolución posterior de la estructura metropolitana hacia tramas urbanas muy diferenciadas, de un lado la racionalidad de las fundaciones hispanas y de otro la irregularidad y sinuosidad del trazado musulmán.

Santiago se ubica junto al río Mapocho (atravesada por este) y al norte del río Maipo, en la planitud de la cuenca a la que la ciudad da nombre, espacio comprendido dentro de la depresión intermedia encajonada por la cordillera de la Costa al oeste (que llega a alcanzar en su punto más elevado los $3.000 \mathrm{~m}$, si bien en este sector central ronda los $1.000 \mathrm{~m}$ ) y la cordillera de los Andes al este (con una altitud promedio de entre $3.000-4.000 \mathrm{~m}$ y con cimas todavía más elevadas en las que destaca el Aconcagua con la máxima cota, $6.960 \mathrm{~m}$ ), mientras que al norte lo hace por el cordón montañoso de Chacabuco $(1.850 \mathrm{~m})$ y por el sur por los cerros de Paine $(2.448 \mathrm{~m})$. La climatología que afecta a la gran metrópoli se resume en un clima templado de $14,5^{\circ} \mathrm{C}$ de media anual, con precipitaciones que apenas superan los $350 \mathrm{~mm}$ al año, mientras que el valle longitudinal está surcado por numerosas corrientes fluviales de régimen nivopluvial, que durante el deshielo ven incrementados sus caudales transportados de forma excepcional, que convergen en el río principal, el Maipo; entre las que destaca el río Mapocho, curso que atraviesa el área urbana de la capital chilena. 
Murcia, de igual forma, se emplaza junto al río Segura en el fondo de la llanura aluvial que conforma parte del valle al que da nombre este curso, concretamente en el tramo conocido como «Vega media», depresión que queda enmarcada al norte por las sierras de Ricote $(1.122 \mathrm{~m})$ y la Pila (1.264 m), al noreste por la sierra de Orihuela (634 m) y al sur por la sierra de Carrascoy $(1.065 \mathrm{~m})$. De este modo, entre la zona de valle y las cimas más elevadas en las que se haya encajado, se dan diferencias altimétricas superiores a los $1.000 \mathrm{~m}$. La climatología dominante ofrece unas temperaturas medias anuales próximas a los $18^{\circ} \mathrm{C}$, mientras que las lluvias apenas superan los 300 $\mathrm{mm}$ al año, con una distribución temporal y volumétrica bastante irregular, con episodios pluviométricos de alta intensidad, característicos de la región y que históricamente han dado lugar a importantes crecidas. De acuerdo con esto, la depresión está dominada por el río Segura, curso fluvial de régimen pluvionival que tiene su nacimiento en la sierra del Segura, en concreto en el municipio de Santiago de Pontones (Jaén), cuyos caudales irrigan la Huerta de Murcia desde sus orígenes, viéndose estos incrementados con las aguas del Guadalentín, afluente por su margen derecha que se une a este antes de alcanzar la ciudad de Murcia.

En lo que se refiere a la estructura urbana y a las cifras demográficas, las ciudades presentan datos muy contrastados que resultan especialmente llamativos, ya que la dimensión de estos es inversa a la antigüedad de cada una de ellas, es decir, mucho más elevados en la capital de Chile. De este modo, actualmente y según los datos del Instituto Nacional de Estadística de cada país, en el área metropolitana de Santiago los valores se corresponden con casi $838 \mathrm{~km}^{2}$ y más de 6.257.516 habitantes ${ }^{1}$, mientras que el continuo urbano de Murcia ocupa $14 \mathrm{~km}^{2}$ y en ella residen 447.182 habitantes, aunque en sus proximidades presenta un importante número de viviendas diseminadas dispersas por toda la zona de la huerta tradicional. Esta enorme diferencia manifiesta un incremento poblacional muy distinto durante las cerca de cinco centurias de historia de la ciudad de $\mathrm{Santiago}^{2}$, desde su origen en la época colonial, y los casi doce siglos transcurridos desde la fundación de Murcia en época musulmana hasta la actualidad; si bien es evidente que estas cifras se ven condicionadas por el hecho de que la primera es una gran capital nacional de
Sudamérica y la segunda una capital regional, que si bien es la ciudad más poblada de su comunidad, en comparación con otras del país posee un tamaño medio.

\section{El río como elemento de fundación}

Evidentemente, la proximidad a un recurso de agua permanente es, para cualquier comunidad, un condicionante esencial en el proceso de selección de asiento. Además, las avenidas enriquecen el llano de inundación mejorando la fertilidad del territorio de manera más que significativa, hecho esencial para su uso productivo. En los dos casos que se analizan, los núcleos fundacionales ocuparon espacios contiguos a un curso fluvial de caudal importante, en Santiago el río Mapocho y al sur-aunque más alejado-el Maipo, ambos con un recorrido de este a oeste; y en Murcia, el río Segura, cuya corriente circula de oeste a este. De acuerdo con esto, desde el origen de las dos ciudades, parte de estas corrientes fueron captadas para su uso agrícola, doméstico e industrial; aprovechamiento pleno que se ha mantenido hasta la actualidad, preferentemente en lo que se refiere a su empleo para el riego de los espacios huertanos creados a partir de los citados recursos hídricos, pues a día de hoy, el abasto generalizado de agua potable en las viviendas y el desuso de esta en las ciudades como energía cinética empleada en la industria molinar, ha relegado al recuerdo estas últimas prácticas ancestrales cuyas huellas, no obstante, aún son visibles en el territorio y, cómo no, han sido parte esencial de la evolución de ambas áreas pobladas y urbanizadas.

En Santiago, tal y como sostiene Figueroa $(2012,2015)$, parte del espacio que hoy ocupa la gran metrópoli contó, previamente a la colonización española, con asentamientos indígenas que hicieron uso primitivamente de las aguas del Mapocho por medio de distintos canales. De esta forma, tanto la civilización chincha-diaguitas como los incas tiempo después, constituyen los primeros pobladores de los que se tiene constancia que aprovechasen dichos caudales del curso fluvial para abastecerse con el objeto de lograr un sustento agrario vital necesario. En este estado, dicha infraestructura hidráulica nativa, cuyo inicio se conoce que se sitúa a la altura de lo que hoy es El Arrayán, es: «La que utiliza el colonizador europeo para fundar el emplazamiento propicio para el pequeño campamento

\footnotetext{
${ }^{1}$ No se han comparado los valores con el área metropolitana de Murcia porque esta no supone un continuo urbano semejante al de Santiago, donde el espacio ocupado no se rompe prácticamente en ningún momento, al contrario que en el primer caso en el que este se compone de distintas poblaciones separadas entre sí por importantes vacíos pertenecientes al espacio tradicional de huerta, aunque existen viviendas diseminadas que complementan el hábitat concentrado de los principales núcleos.

${ }^{2}$ Los trabajos del arquitecto Profesor Jonás Figueroa Salas (Figueroa, 2007, 2009, 2012 y 2014), constituyen obras de referencia fundamentales para entender la influencia del agua como elemento determinante en la configuración de la ciudad de Santiago.
} 


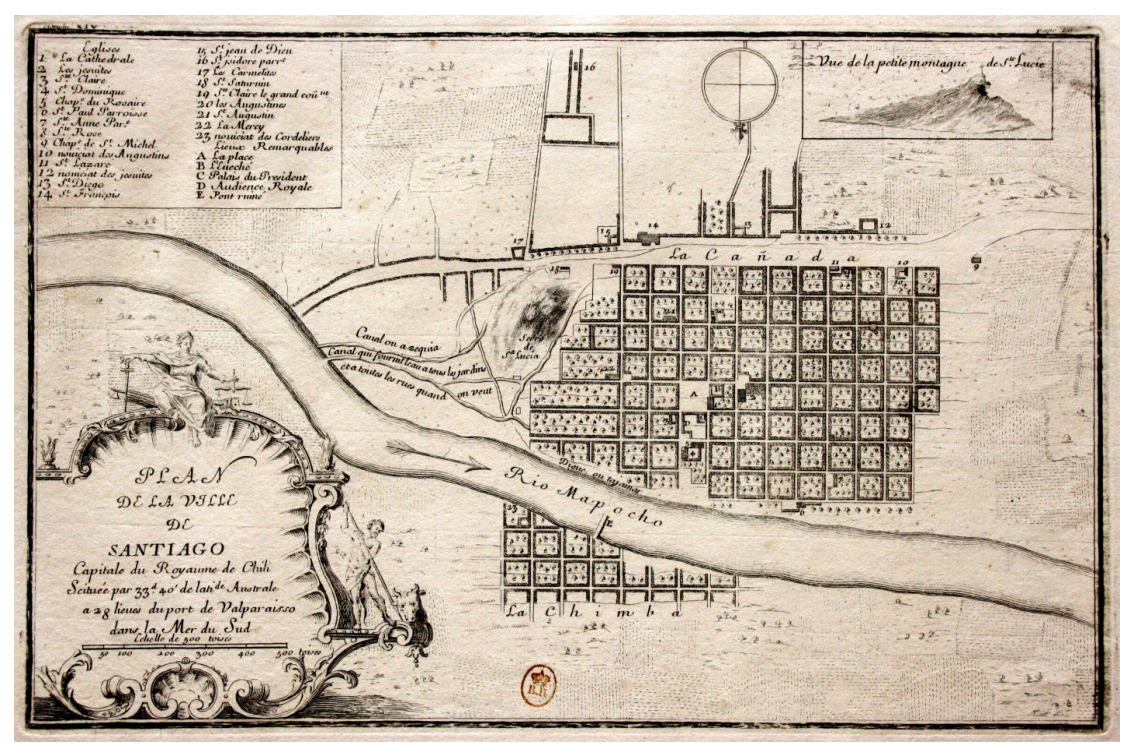

Figura 1. Santiago en el s. XVIII y los canales que abastecían al espacio agrícola y urbano con las aguas del Mapocho. Fuente: Archivo Histórico Nacional de Chile, custodia en la Bibliothèque Nationale de France.

militar, como prólogo de la división de la tierra que será asignada según el rango y contrato de la hueste colonizadora. Cuando el valle se hace castellano por la aplicación de las ordenanzas de población de las Leyes de Indias, las aguas del Mapocho y de la Cañada son determinantes para fundar en la isla protegida por el peñón del Santa Lucía y por los dos cursos demarcada, el núcleo urbano inicial cumpliendo rigurosamente lo determinado por la letra y el espíritu de la ley» (Figueroa, 2015. p. 18).

En consecuencia, se conoce que parte de las aguas de este río, en origen, eran captadas por medio de tres acequias principales o canales que permitían el riego, no solo de una importante superficie circunscrita al área urbanizada inicial, sino también en el interior de esta, ya que la red hidráulica se internaba en la propia trama urbana por medio tanto de los referidos canales como de acequias menores, tal y como se aprecia en el Plan de la ville de Santiago capitale du Royaume de Chili, de Amadee François Frezier de 1716 (Figura 1). Las tres conducciones indicadas se corresponden con la acequia de Nuñoa (también conocida como de Tobalaba o Apoquindo), la de Vitacura y la de Incagorongo. La primera regaba el área este de la ciudad desde la falda de los Andes hasta los campos de Macul; la segunda circulaba por la base del Cerro de San Cristóbal y abastecía la zona noroeste donde se encontraban los campos de Conchalí, Huechuraba y Quilicura; por último, la tercera lo hacía en los terrenos situados al suroeste y oeste de Santiago, donde irrigaba el área de Los Cerrillos (Figueroa, 2009,2015).

Con el tiempo, la propia dinámica urbana y demográfica del enclave favoreció, a lo largo de los siglos precedentes, el aumento del número de canales y acequias, garantizando con ello la aportación o abastecimiento a un mayor número de habitantes y a una superficie ocupada en continua ampliación, cuyo crecimiento físico más reciente se produce sobre la propia red de canales y acequias, incidiendo sobre las morfologías urbanas instaladas sobre el extrarradio agrícola, tal y como apunta Figueroa (2012). En este sentido, en los siglos XIX y XX se considera que existieron hasta veinticuatro acequias principales, obviamente construidas en distintos momentos tanto del periodo colonial como posteriormente en época republicana; de modo que el incremento del espacio agrario dotado de caudales captados de los ríos circundantes es más que significativo.

Al margen de esto, al sur del emplazamiento urbano y a una distancia considerable de su perímetro primario, se captaban las aguas del Maipo mediante distintos canales que nutrían terrenos situados al sureste de Santiago, como son los de Isla de Maipo, Lonquén, Malloco y Tango, Talgante y Pencudaña Peñaflor. Una explotación agrícola que tuvo su máximo hito con la definitiva puesta en funcionamiento del canal de derivación conocido como Canal de San Carlos o Canal de Maipo. Una obra cuyos 


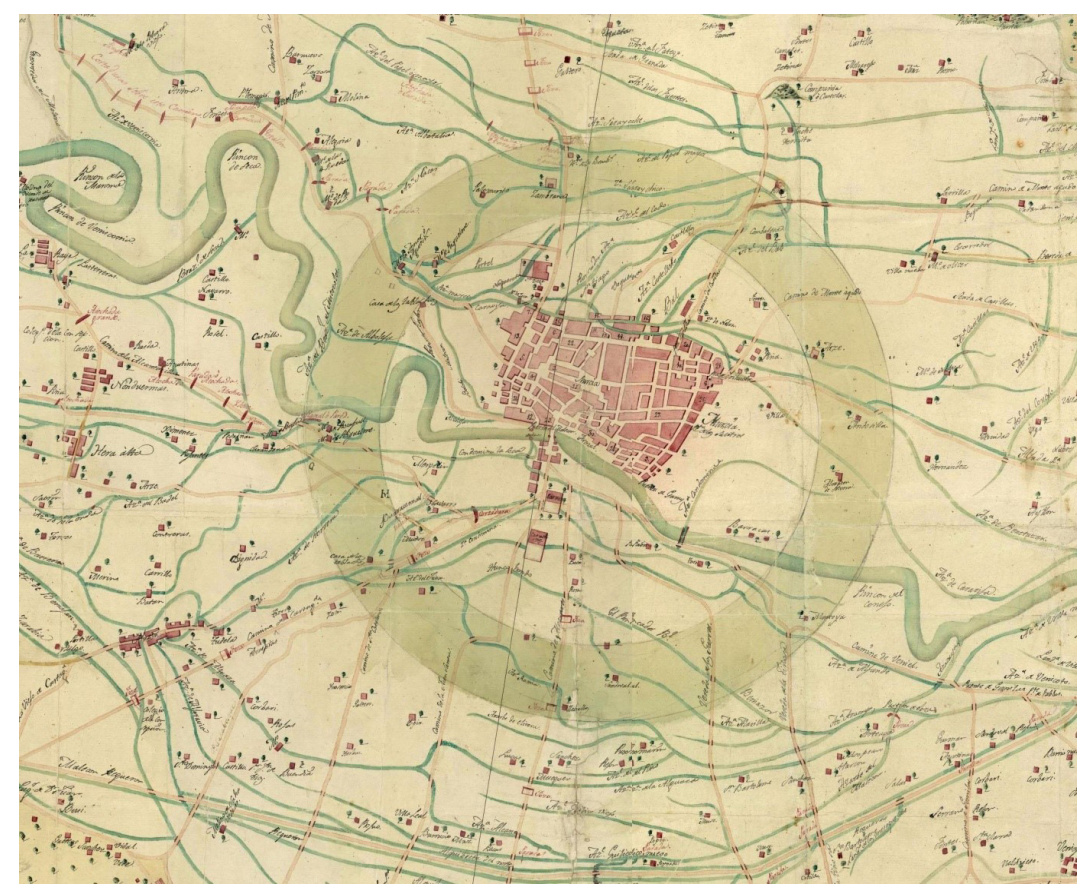

Figura 2. Murcia en el siglo XIX rodeada de las múltiples acequias que regaban su huerta a partir de las aguas del Segura. Fuente: Biblioteca Virtual del Patrimonio Bibliográfico, custodia en la Cartoteca del Archivo General Militar de Madrid.

primeros intentos de realización se sitúan a mediados del siglo XVIII, si bien no fue hasta 1820 cuando este se inauguró parcialmente y hasta 1825 cuando entró en pleno funcionamiento. En este estado, dos años después, la canalización fue vendida por la administración pública a una entidad privada, momento en que se constituye la Sociedad del Canal de Maipo, ente encargado, desde entonces, de gestionar tanto la infraestructura hidráulica como los caudales. Además, poco tiempo más tarde, en 1835, se inicia la construcción de un segundo canal que se conoce con la denominación de Canal de Eyzaguirre, otra de las importantes infraestructuras hidráulicas que abastecieron al espacio irrigado situado al sur de la ciudad, sinónimo del crecimiento urbano, demográfico y agrícola del área en cuestión.

Por otro lado, en lo que concierne a Murcia, la captación de las aguas que abastecen a la red de riego de la huerta, cuyas obras se iniciaron en las primeras décadas del dominio islámico (siglo IX), se inicia en la presa de la Contraparada, $a z u d^{3}$ de derivación desde el que parten las dos acequias mayores o principales que nutren el complejo hidráulico: la Acequia de la Aljufía, en la margen izquierda y que abastece al llamado Heredamiento norte, y la Acequia de la Alquibla, en el lado derecho del citado cauce y que dota al conocido como Heredamiento sur.

A partir de ambas canalizaciones se construyeron otras menores que, en conjunto, completan el sistema de transporte de los recursos hídricos hacia todas y cada una de las parcelas explotadas antaño en el espacio indicado y externo al área amurallada, aunque en el interior de este existieron, en tiempos pasados, jardines y limitados espacios de cultivo asociados a patios reducidos de determinadas residencias. Además de este entramado de acequias de entrada de aguas, existe otro de sentido inverso que recoge las sobrantes del riego del terreno y las devuelve al río, conducciones que, por orden de importancia, son conocidas como escurridores, azarbetas, azarbes y azarbes mayores y que tienen tanto una existencia subsuperficial o subterránea, como a cielo abierto. Un conjunto hidráulico cuya dimensión es claramente visible en el detalle del Plano que manifiesta la Huerta de Murcia, preparada para ynundarla caso de ser amenazada de Ymbación la Capital pr. ls. enemigs. elaborado por Pablo de Villar en 1809 (Figura 2).

${ }^{3}$ Del ár. hisp. assúdd, y este del ár. clás. sudd. Barrera hecha en los ríos con el fin de facilitar el desvío de parte del caudal para riego y otros usos (DRAE). 
De este modo, la Huerta de Murcia y su espacio agrario contiguo y conexo, la Huerta del Bajo Segura, conforman un sistema de riego de aprovechamiento y reaprovechamiento de enorme eficiencia, muestra extraordinaria de la utilización y reutilización del recurso hídrico, a la que, además del patrimonio material, está ligado un impresionante valor inmaterial que se remonta a la ocupación musulmana del emplazamiento. Obviamente, se trata de una red de irrigación y drenaje en uso durante los más de mil años transcurridos desde su origen, hecho que demuestra su eficacia e importancia en el territorio, pero que, en las últimas décadas está sufriendo una importante transformación y deterioro debido a la mutación del espacio agrario tradicional en un espacio urbano que constriñe estos campos de cultivo, lo que García \& Canales (2018) han definido como la «huerta sitiada».

Así, tanto en el caso chileno como en el español, el aprovechamiento mencionado de los caudales de los cauces próximos a los asentamientos supuso no solo el origen o motivo fundacional primordial de estos, sino también, aunque de forma secundaria, el fundamento básico sobre el que se produjo el crecimiento demográfico y urbano, fruto de una mayor expansión agrícola capaz de abastecer a una población en continuo aumento. Asimismo, e indiscutiblemente ligado al incremento poblacional, la corriente de agua transportada por los distintos canales, generalmente los de mayor importancia en la jerarquía hidráulica, fue aprovechada de forma industrial como energía para el accionamiento de diversos molinos hidráulicos -preferentemente de rueda vertical en Chile y de rodezno o rueda horizontal en España- construidos sobre estas canalizaciones y junto al propio río. Estas edificaciones son hoy un referente patrimonial asociado a la red hidráulica y cuya función principal fue la molturación de granos de cereal, fundamentalmente trigo, para la obtención de harinas, alimento de consumo básico para una población creciente; aunque también se utilizaron para otros usos. En Santiago, la presencia más temprana de estas industrias se retrotrae al siglo XVI, pocos años después de la fundación de la ciudad. Conforme a esto, se conoce que el 26 de abril de 1547 el cabildo otorgó autorización al español Bartolomé Flores para edificar un molino «a las tomas de las aguas del cerro de la hermita de Santa Lucía» (Lacoste, 2018, p. 106); sin embargo, otros autores defienden que el primer molino de la ciudad fue erigido en $1548^{4}$ por el capitán del ejército colonizador Rodrigo de Araya y sobre la acequia ubicada al sur del Cerro Santa Lucía (Sahady et al., 2014). Con todo, ya fuese uno u otro, parece ser que estos fueron edificados tomando como referencia los existentes en el país de origen de los conquistadores, y no cabe duda alguna de que a estos inmuebles hidráulicos les sucederán otros levantados en el lugar durante este siglo, fundamentalmente por militares de la hueste española.

De acuerdo con lo indicado, parte del resto de personajes que supieron aprovechar la necesidad y oportunidad para construir estos complejos industriales en este siglo inicial fueron: Juan Jufré, Francisco Riberos y Carlos Molina (Lacoste, 2018), así como también Juan Dávalos y Rodrigo Quiroga; si bien, con los años se construyeron otros tantos por distintas órdenes religiosas -Molino de Santo Domingo y Molino de San Agustín- y otras personalidades (Sahady et al., 2014). El resultado sería la instalación, a lo largo de los siglos, de numerosas explotaciones sobre las diversas acequias que atravesaban la ciudad y abastecían su huerta, ocupándose, de esta manera, de la molienda efectiva de las producciones cerealícolas de la población, esencialmente del trigo, cereal cuya producción encabezó Chile en toda América del Sur desde su introducción por los españoles. No obstante, la evolución de los procesos y técnicas de molturación, así como el propio crecimiento de la ciudad, dejaron obsoletas estas industrias en el siglo XIX, provocando su disfuncionalidad y posterior desaparición en un casco urbano creciente.

Por otro lado, en Murcia, durante el periodo musulmán iniciado con la fundación de la ciudad en el siglo IX, ya se tiene constancia de referencias a molinos accionados por las aguas canalizadas por la red de acequias y azarbes de la huerta, así como también de aquellos ubicados en el propio río a su paso por la próspera urbe. La conquista cristiana lograda en el siglo XIII no hizo más que acrecentar la implantación de nuevas instalaciones de estas industrias, fundamentalmente edificadas y administradas por familias distinguidas, por la iglesia y las órdenes militares, y localizadas tanto a lo largo del río como en las canalizaciones donde se les concedió licencia para ello, generalmente en los dos canales principales citados. Los siglos posteriores consolidarán estas edificaciones y sumarán al conjunto otras tantas, de modo que, en el siglo XX, última centuria en la que estuvieron en funcionamiento, tan solo en las dos acequias nombradas existía casi una treintena de molinos, a los que deben sumarse los del cauce del río Segura en el tramo urbano y alguno existente en los canales menores de la malla hidráulica, un gran conjunto molinar que salpicaba prácticamente todo el espacio de cultivo. Además, en este caso, cabe indicar que, pese a

\footnotetext{
${ }^{4}$ Según Lacoste (2018) en este año ya existían cuatro molinos edificados en la capital de Chile.
} 
que la molturación de cereal fue su función primordial, también hicieron lo propio con otros productos, tales como el pimiento para la obtención de pimentón, los distintos componentes necesarios para la fabricación de pólvora, e incluso fueron empleados para confeccionar paños por medio del abatanado.

\section{El río como elemento de destrucción}

Al margen de la concepción del río como fuente de vida y elemento indispensable para comprender los orígenes de las dos ciudades que se analizan, los cursos fluviales que abrazan las urbes señaladas eran y siguen siendo un riesgo potencial para el espacio urbano que las compone y el capital humano que las habita. Forman parte esencial de lo que Calvo (2005) definió como «paisajes del miedo». En este sentido, tanto el río Mapocho como el Segura han sido también, a lo largo de la historia, entidades naturales de grave destrucción y mortalidad debido a sus crecidas; en el primer caso, condicionadas por los deshielos, las lluvias de alta intensidad y la enorme diferencia altimétrica en una pequeña distancia entre la cordillera y el área donde se emplaza la capital nacional, y en el segundo, marcado por un régimen climático caracterizado por la recurrencia de intensos episodios pluviométricos esporádicos que incrementan el caudal de la corriente fluvial de forma exorbitante en un lapso de tiempo muy reducido.

De este modo, considerando la situación de vulnerabilidad en la que se encontraban ambos asentamientos, sus responsables llevaron a cabo, siglos atrás, la construcción de sendos sistemas defensivos para minimizar el impacto de las crecidas; un nuevo paralelismo entre las dos ciudades. Sumaron, por tanto, a su condición idéntica sustancial de «ciudades por el agua» aquella cualidad antagónica pero indisoluble de la identidad que las caracteriza, la de «ciudades contra el agua»; dicotomía que no solo constituye un impacto material, físico y visible, resultado de la adaptación del ser humano al medio, sino que resulta elemental para comprender el valor inmaterial del sentimiento colectivo de la sociedad que convive con la amenaza constante de la naturaleza. De acuerdo con ello, este hecho da pie a una «Cultura del Agua» enriquecida tanto por el aprovechamiento máximo de esta mediante las distintas redes hidráulicas y sus elementos asociados, como una obra defensiva de enorme envergadura que guarda a la población de la recurrente catástrofe.

En Santiago, esta acción se corresponde con el conocido como «Tajamar», obra que Figueroa (2009) acertadamente definió como el «pretil que protege la ciudad de los embates violentos de las aguas» (p. 58). No obstante, esta sólida defensa artificial, al igual que ocurrirá en la ciudad de Murcia, supone un constructo humano fruto de la evolución histórica de la necesidad de proteger a los habitantes; una intervención que, indudablemente, ha ganado en solidez y eficacia a medida que se han sucedido los siglos. De esta forma, la muralla de obra como tal no comienza a construirse hasta los primeros años del siglo XVIII. Hasta entonces, la única actuación testimonial que habían llevado a cabo los pobladores para controlar el libre correr del río por el valle, ocupando un vasto cauce tan ancho como otros ríos de esta depresión central, fue la construcción de parapetos de piedra y troncos en aquellos puntos conflictivos en los que el agua solía golpear con mayor ímpetu, siendo esta tipología de actuaciones, junto con la fábrica y limpieza de los canales, las principales obras públicas acometidas por la autoridad colonial.

De acuerdo con lo manifestado y en base a lo señalado por Ayarza (2013), esta situación se altera en 1700 cuando el gobernador Ortiz de Rosas autoriza la construcción de un muro (tajamar o malecón) mediante obra de mampostería en la que se hizo uso del ladrillo cerámico de arcilla como material fundamental de edificación. De esta forma, el débil murallón inicial es sustituido por un trabajo de ingeniería hidráulica de envergadura y, obviamente, con una resistencia mucho mayor a las embestidas furiosas del río Mapocho; labores que serán ampliadas en 1726. Algunas décadas más tarde, concretamente en 1749, se considera oportuno reedificar parte del Tajamar, haciendo uso, para ello, de la piedra y dando lugar a una obra de dimensiones próximas a $1,30 \mathrm{~m}$ de ancho por $2,20 \mathrm{~m}$ de alto. Estas medidas, sin embargo, resultaron insuficientes para soportar una avenida extraordinaria ese mismo año que provocó graves desperfectos que no serían reparados hasta 1765 , año en que se iniciaron las labores de reconstrucción y remodelación ejecutadas bajo las órdenes de Juan Garland y momento en el que, además, se construyó un muro secundario en la margen opuesta del río a donde tradicionalmente se habían llevado a cabo las actuaciones usuales de protección.

Por desgracia, una gran crecida sucedida en 1783 destruye prácticamente todo el conjunto defensivo y obliga a las autoridades a buscar una nueva solución efectiva al problema. El gobernador Ambrosio Benavides encomienda entonces al arquitecto Joaquín Toesca la reparación de la barrera artificial, quien, mientras se discutía la financiación y cuantía disponible para la obra, decide construir una empalizada protectora mediante troncos que perdurará casi una década. Alcanzado 1788, Ambrosio O'Higgins toma el mando de la gobernación y encarga el diseño de las obras de protección al arquitecto e ingeniero militar 


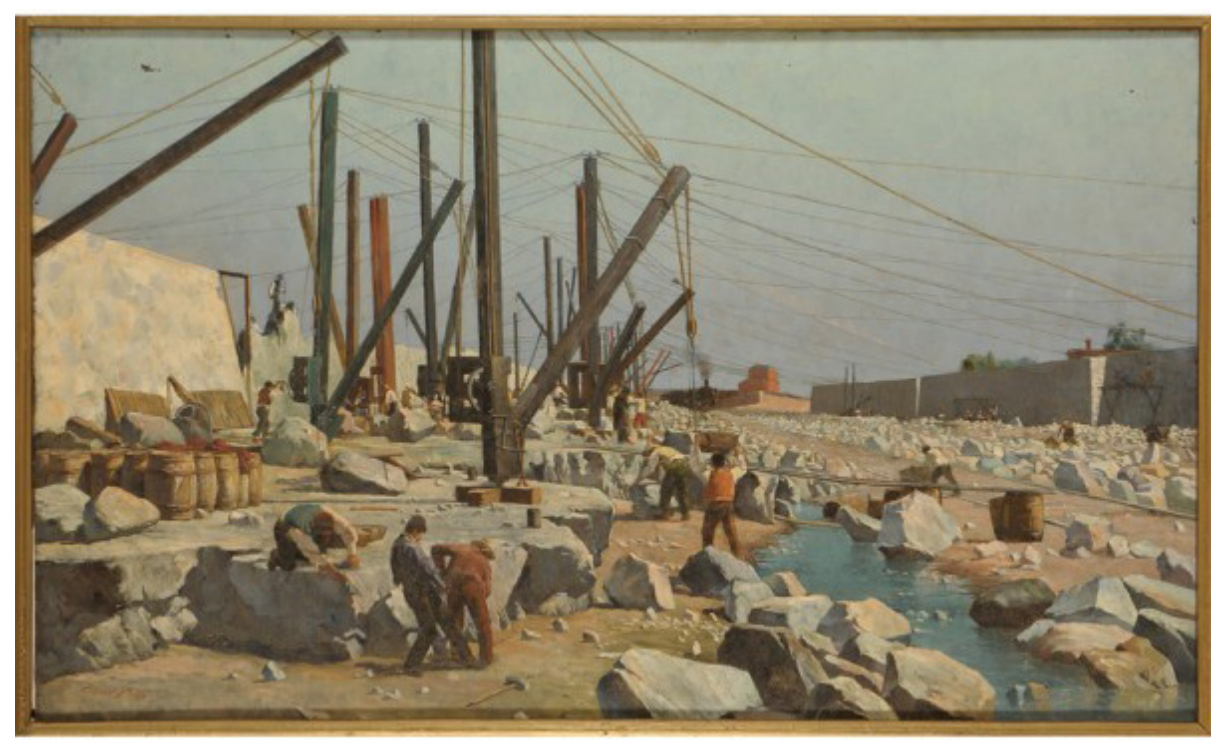

Figura 3. Construcción de los Tajamares del Mapocho, 1890. Fuente: Archivo Histórico Nacional de Chile, custodia en el Museo Histórico Nacional.

Leandro Barandán ${ }^{5}$, sobre cuyo plano comenzará las obras en 1792 el ya referido Joaquín Toesca, encargado de las labores hasta su fallecimiento en 1799 , cuando fue sustituido primero por Agustín de Caballero y posteriormente por Ignacio Santa María, bajo cuya dirección culminarían, en 1808 , las tareas proyectadas. En este caso, se correspondía con un murallón de ladrillo de 1,60 $\mathrm{m}$ de ancho y 5,00 m de alto que dio lugar a un paseo peatonal que sirvió, en cierto modo, como lugar de tránsito de los vecinos de la capital chilena (Ayarza, 2013).

A pesar del enorme esfuerzo llevado a cabo a lo largo todo el siglo XVIII, en el siglo XIX esta obra fue, en parte, derruida con la ejecución de las labores de canalización del río Mapocho realizadas entre 1886 y 1891, y reflejadas por Rafael Correa en su pintura titulada «Canalización del río Mapocho» fechada en 1890 (Figura 3). Dichas tareas fueron impulsadas en 1872 por el intendente de Santiago, Benjamín Vicuña Mackenna, quien ordenó la realización del proyecto al ingeniero M. Ansart con el fin de mejorar las defensas contra el río e incorporar, de manera efectiva y al estilo europeo, el curso fluvial a la ciudad como recurso de esparcimiento y disfrute social. No obstante, no fue hasta después de la Guerra del Pacífico y gracias a los ingresos de las explotaciones salitreras, cuando se ejecutó el plan bajo la presidencia de José Manuel Balmaceda y la supervisión del recién creado Ministerio de Industria y Obras Públicas. A su vez, la propia solidez de la nueva estructura influyó en la instalación de distintos puentes de acero en los años posteriores que sustituyeron a los de madera y mejoraron la conectividad entre ambas orillas, preferentemente la conexión de la ciudad con el antiguo barrio de La Chimba.

Finalmente, a principios del siglo XX otra parte importante de los tajamares fue sepultada con la construcción del Parque Forestal inaugurado en el año 1905, perdiéndose así todo testimonio de las antiguas edificaciones contra las avenidas, hasta que han reaparecido recientemente en distintas obras públicas y privadas ejecutadas en la capital de Chile y que han devuelto parte de la infraestructura a la superficie a modo de vestigios históricos. De acuerdo con esto, existen fragmentos del Tajamar en diferentes espacios públicos de la capital como son la entrada del Museo de los Tajamares, las Torres de la Avenida Portugal, calles Ismael Valdés Vergara con Mac-Iver, en el Parque Forestal y al sur del puente Recoleta, en las proximidades de los aparcamientos subterráneos.

\footnotetext{
${ }^{5}$ En un fragmento de tajamar existente en el Parque Forestal de la ciudad de Santiago, existe una placa que válida esta afirmación y en la que se puede leer «Este trozo de mampostería perteneció a los antiguos tajamares del río Mapocho que ordenó construir el Gobernador del Reino de Chile Don Ambrosio O’Higgins en el año 1791 basado en los planos de Leandro Baradán modificados por el arquitecto Joaquín Toesca».
} 
En Murcia, aunque, en origen las motas -recrecimientos térreos de las márgenes- del río contenían los ascensos del caudal cuando estos no eran muy importantes, de manera artificial las murallas de la medina islámica ya cumplían cierta función de protección contra las avenidas debido a su imponente factura arquitectónica ${ }^{6}$. También coadyuvaba la propia red de riego del espacio huertano que actuaba, en cierto modo, como elemento laminador de las avenidas. No obstante, se trataba de una protección claramente insuficiente y en el siglo XV se construye una nueva obra diseñada exprofeso contra las crecidas del río Segura, el llamado «Malecón»" ${ }^{7}$, cuyas labores de edificación parece ser que se iniciaron en 1420 debido a los desperfectos causados por una riada acaecida ese mismo año (López, 1978).

En origen, esta barrera de tierra, ejecutada entonces desde la Puerta del Puente hasta la acequia Aljufía, se correspondía con un gran muro levantado en el lado izquierdo del curso, margen donde se encontraba ubicada la ciudad y los distintos arrabales o barrios erigidos extramuros del cerco defensivo urbano principal, edificaciones, por este motivo, en mayor riesgo. Un muro en cuyas reparaciones participaban los propios vecinos de la ciudad por mandato de las autoridades que la regían ${ }^{8}$ y cuyo estado óptimo era una preocupación de primer orden tanto para el Concejo de Murcia como también para la propia población, lo que explica las numerosas propuestas de recrecimiento o alzado del mismo para hacer más eficaz su función (Torres \& Calvo, 1975).

Con todo, las sucesivas crecidas y el carácter térreo que definía la obra, hicieron que esta necesitase de continuas reparaciones y acrecimientos durante los siglos posteriores tras avenidas importantes, ya que el agua, en ocasiones, se abría paso por los puntos débiles y terminaba anegando importantes áreas anexas al cauce fluvial. Este hecho, además, presentaba un grave problema epidemiológico ante la imposibilidad, en ciertos puntos, de retorno del agua al cauce, lo que dio lugar a episodios palúdicos de gravedad (Castejón, 2015). En este sentido y a pesar de la situación de continua recomposición del murallón de tierra e intentos anteriores, importantes pero infructíferos, no fue hasta tres siglos después de los primeros trabajos documentados sobre esta intervención humana cuando se subsanó la necesidad y urgencia de reforzar este sistema defensivo contra el agua mediante una actuación que permitiese una consolidación de este más efectiva y duradera. Esta labor requería, además de un ingenio suficiente demostrado desde época islámica, también de una inversión muy importante y que en parte fue posible gracias al esplendor económico de la urbe, en este momento fundamentado en el gran incremento de la explotación agrícola de su huerta, con especial incidencia en lo que se refiere a la producción de seda.

De esta forma, pasada la grave avenida de 1701 -que produjo cuantiosos daños no solo en la infraestructura defensiva- y realizados los trabajos de acorte de meandros llevados a cabo en 1711 y 1725 (Escalpez, 2016), en 1735 (López, 1978) y gracias al corregidor Francisco de Luján y Arce, arranca una importante reedificación del antiguo Malecón con la que se consiguió incrementar su capacidad de protección y se inició la concepción de este espacio como un lugar de ocio y esparcimiento. Es en este momento cuando el río comienza a considerarse como un «paisaje fluvial» y así se percibe en el grabado de J. F. Palomino incluido en la obra Atlante español o Descripción general geográfica, cronológica e histórica de España, por reynos y provincias (Tomo I, Reyno de Murcia) publicada por Bernardo Espinalt y García en 1778 (Figura 4).

La citada intervención se basó en la consolidación de un revestimiento pétreo sobre el muro, mucho más resistente que la tierra al envite de las aguas, el ensanche de la propia muralla y la modificación de sus pendientes dándole más robustez. Además, se adosó un camino por la parte inferior de la misma por el que se obligó al tránsito de toda clase de caballerías para evitar desperfectos en el murallón, usual paso para la población debido a su planitud y fácil circulación. A todo esto, se debe sumar la implantación de las Ordenanzas del Malecón, aprobadas de acuerdo con la Real Provisión del Supremo Consejo expedida en 30 de agosto de 1737, normativa que regulaba el uso y actuaciones permitidas que pudiesen afectar a la nueva

\footnotetext{
${ }^{6}$ En este sentido, ya en el siglo IX la ciudad contaba con un sólido recerco murado, si bien es entre el siglo XI-XII cuando se incrementa la capacidad defensiva del contorno fortificado -algunos autores señalan que influenciado por el esplendor de la época de gobierno de Ibn Mardanis en este último siglo- caracterizado entonces por una antemuralla de varios metros de altura y una imponente muralla de más de diez metros de alto y $2.000 \mathrm{~m}$ de perímetro que se calcula llegó a contar con más de noventa torres y se conoce que tuvo nueve puertas o accesos; obra, en su conjunto, construida mediante encofrado de tapial de hormigón y calicanto.

${ }^{7}$ Según la Diccionario de la RAE Malecón es «Murallón o terraplén que se hace para defenderse de las aguas», misma definición que aplica en Tajamar para la que sostiene: «Chile y C. Rica. malecón (murallón para defenderse de las aguas)»; por lo tanto, son sinónimos.

${ }^{8}$ Como ocurrió en 1465 (Torres \& Calvo, 1975)
} 


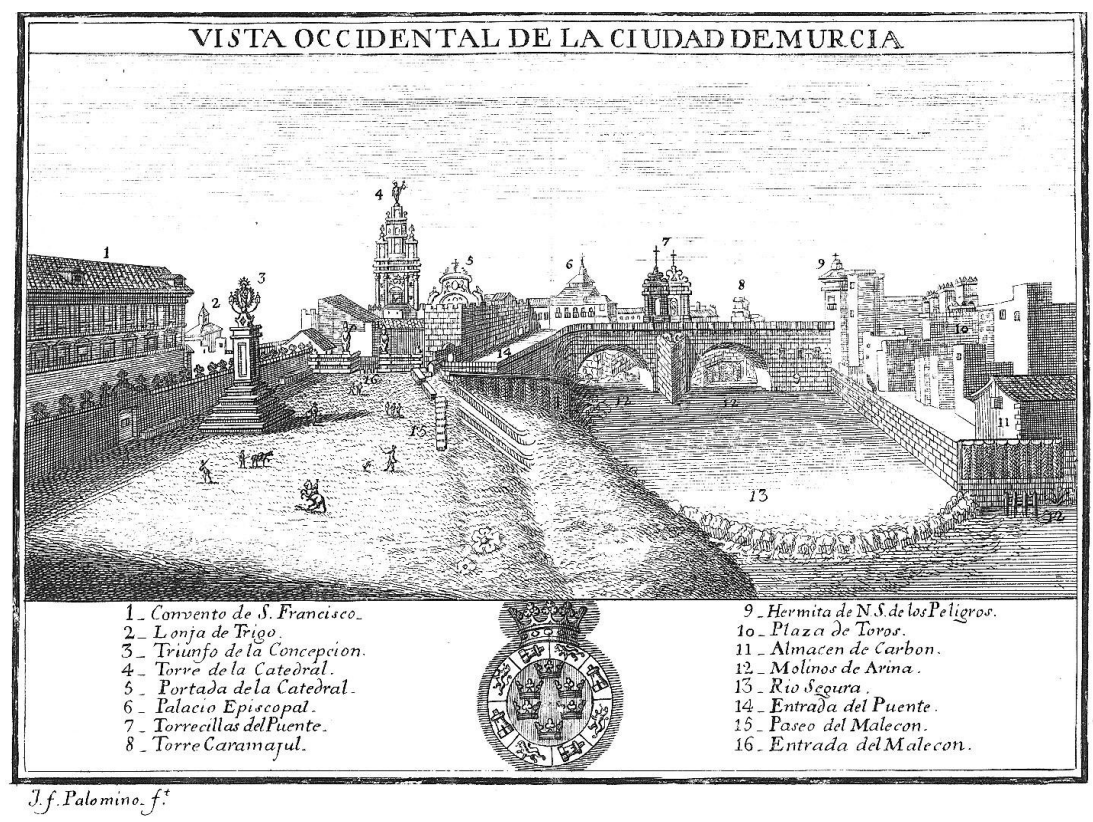

Figura 4. El Malecón de Murcia como obra de defensa y lugar de socialización antes de la avenida de 1787. Fuente: Biblioteca Virtual del Patrimonio Bibliográfico, custodia Biblioteca Regional de Murcia

obra con el objeto de preservar su estado en las condiciones deseadas (Peñafiel, 1993); circunstancia que refleja, sin duda, el interés patente en la preservación de esta.

Medio siglo más tarde, en 1785 y comisionado por Carlos III, el conde Floridablanca -secretario de Estado del Gobierno español y natural de Murcia- auspicia un nuevo proyecto de mejora de la defensa de la ciudad que será diseñado por el arquitecto Manuel Serrano y ejecutado por el maestro mayor Ceferino Enrique de la Serna y Sierra. Dicho planteamiento, formaba parte de un plan más amplio cuyas actuaciones principales eran: el derribo de distintos elementos que obstaculizaban la libre circulación de las aguas (entre ellos el Molino del Batán y el Molino de Las Coronas), la construcción de un edificio molinar de hasta veintiuna piedras que supliese a los demolidos, la edificación de la Posada del Puente o Casa de las Posadas y la reedificación de la muralla del río. Conforme a esto, en lo que concierne a la obra de defensa y tomando lo señalado por Calvo (2005):

«La propuesta del arquitecto Serrano [...] supone encauzar el río, construyendo muros en ambas márgenes, proporcionándole un trazado más rectilíneo y manteniendo una anchura de cauce prácticamente homogénea, de unos $70 \mathrm{~m}$, en un tramo más largo que el dotado de muros [...] Sobre el flanco derecho del río, el encauzamiento previsto permite recuperar una franja de terreno suficientemente amplia para que el arquitecto desarrolle un interesante proyecto a la vez urbanístico y de ordenación territorial [...] Respecto al acondicionamiento de la ribera, se proyecta la construcción de una muralla en ángulo recto que engloba el "arrabal de afuera", cuya finalidad es la defensa tanto frente a crecidas del Segura como de los caudales que provienen del Sangonera, la cual concluye en el puente». (p. 36)

De esta forma, el río fue flanqueado por dos grandes muros de sillería de prácticamente una decena de metros -como se haría en Santiago con el Mapocho- aunque existía una considerable diferencia arquitectónica entre el muro de la margen derecha -que salvaguardaba el creciente barrio de El Carmen ${ }^{9}$ - y el de margen izquierda o contiguo a la ciudad que contó con un cuidado mayor en su terminación

\footnotetext{
${ }^{9}$ Una vez más, resulta curioso este paralelismo referido a la existencia de un barrio importante al otro lado del cauce en el que se situaba la urbe y que fue protegido de forma secundaria, en el caso de Santiago el conocido barrio de La Chimba y en el de Murcia el de El Carmen.
} 
de perfil trapezoidal y un remate de barandilla. Además, es indispensable indicar que, como se cita tanto en el proyecto como en los análisis urbanísticos posteriores, la intervención dio lugar a una remodelación importante de los espacios y edificaciones lindantes al cauce en este tramo, reforzando la intención de conexión entre la urbe y la corriente hídrica como paisaje y entorno de ocio útil, es decir, tal y como señala Escalpez (2016) se le dotó de «carácter defensivo y estético» (p. 14), como ocurriría con el entorno del Mapocho en su momento. Además, la mayor estabilidad propició la nueva construcción de puentes y pasarelas sobre el curso que conectaban ambas orillas, especialmente el puente de Los Peligros, tal y como sucedió en Santiago, destacando entre estos el puente de Calicanto. No obstante, una vez más, las obras resultaron ser insuficientes y en 1787 una crecida obligó a realizar numerosas reparaciones en el Malecón debido al ímpetu con el que las aguas golpearon la defensa.

La consolidación temporal de la obra como protección y lugar de ocio fue la tónica dominante en el siglo posterior, la centuria del XIX. Así, esta misma condición de espacio de socialización y divertimento frecuentado por las élites locales supuso el aliciente suficiente para que sobre el mismo se llevasen a cabo diversas actuaciones de mejora del ornato con la intención de hacerlo todavía más atractivo $\mathrm{y}$ acorde a una sociedad en auge, tal y como se mantuvo en el siglo XX. Conforme a esto, dentro de las propias actuaciones de mejora del entorno del Malecón o uso de este como recurso de los residentes en la capital, cabe destacar la creación, en 1845, del Jardín Botánico, área académico-natural vinculada al Instituto Provincial de Murcia y lugar de práctica de las cátedras de Agricultura y de Historia Natural del mismo; espacio que sería el antecedente del espacio de parque ajardinado actual.

De esta forma, el Malecón, su paseo y el entorno verde creado junto al mismo en algunos puntos, ha llegado al siglo XXI con este mismo carácter de lugar de esparcimiento y muro de defensa contra las avenidas, hoy día controladas de forma más efectiva, entre otras cosas por la construcción en la centuria anterior de los embalses de Alfonso XII y Cenajo. Por otro lado, y al margen de lo indicado, cabe destacar que, en el caso de la capital de la Región de Murcia, además de la barrera arquitectónica de protección ya señalada, desde el siglo XVI se propusieron diversas actuaciones de modificación estructural de los cauces. Este fue el caso de la posibilidad descartada de reconducir el Guadalentín hacia el mar aguas arriba de su confluencia con el Segura o la definitiva construcción del Canal del Reguerón en el siglo XVIII a cargo del ingeniero militar Sebastián Feringán (Calvo, 2005); obra iniciada en 1733 y todavía funcional que deriva las aguas de la primera corriente desde el llamado «Paso de los Carros» y las devuelve al río Segura en el Rincón de Villanueva, aguas abajo de Murcia; reduciendo con ello el impacto de la confluencia hídrica en la ciudad ${ }^{10}$.

\section{Protección de un patrimonio monumental}

Más allá de la ciudad como constructo humano, resultado de la simbiosis de esta con el río en las dos capitales de estudio, como no podía ser de otra manera, tanto la red de riego como la obra de defensa merecen indiscutiblemente el calificativo de «patrimonio» -así como toda aquella cultura material e inmaterial ligada a estos dos elementosentendido este como el conjunto de bienes culturales y naturales heredado, tangibles e intangibles, que permiten entender y conocer la historia, las costumbres y las forma de vida hasta la actualidad. Sobre esta base se construye la memoria colectiva, la identidad y un paisaje concreto, posibilitando la asociación con una cultura y una forma de vivir específica, lo que constituye, de este modo, el legado recibido y que se transmitirá a las generaciones venideras.

En lo que se refiere a Santiago, tanto la obra vital como la obra defensiva poseen una figura de protección amparada en la Ley 17.288 de Monumentos Nacionales, normativa específica que vela, desde su promulgación en 1970, por la defensa del patrimonio cultural y natural de Chile, y que, como su propio nombre indica, constituye el conjunto de disposiciones legales establecidas para la identificación, resguardo, conservación y puesta en valor de bienes considerados de alto valor y que hayan sido identificados como «Monumentos Nacionales».

En este sentido, la referida legislación establece cinco figuras de salvaguarda englobadas bajo esta denominación y que se corresponden con las de: monumento arqueológico, monumento histórico, monumento público, zona típica o pintoresca y santuario de la naturaleza, siendo la primera de ellas la atribuida a las infraestructuras estudiadas y cuya definición aparece recogida en el Título V Artículo $21^{\circ}$ de la misma (página 18) del siguiente modo: «Por el solo ministerio de la ley, son Monumentos Arqueológicos de propiedad del Estado los lugares, ruinas, yacimientos y piezas antropo-arqueológicas que existan sobre o bajo la

\footnotetext{
${ }^{10}$ Esta obra de ingeniería hidráulica, en inicio, no fue lo suficientemente efectiva ya que no se diseñó para conectar con el río Segura sino para que vertiera la crecida en parte de la huerta, circunstancia subsanada posteriormente con la conexión al cauce principal.
} 
superficie del territorio nacional». Es decir, el mero hecho de su existencia las ampara bajo la defensa y vigilancia estipulada por la indicada normativa.

No obstante, ni los antiguos canales de riego ni el Tajamar aparecen contemplados en las relaciones de bienes distinguidos por el Consejo de Monumentos Nacionales $(\mathrm{CMN})$ o el Servicio Nacional de Patrimonio Nacional (Castejón, 2019). Con todo, es cierto que la malla hidráulica primitiva prácticamente ha desaparecido en el extenso espacio urbanizado de la capital de Chile y su conurbación, del mismo modo que lo ha hecho el paisaje huertano o de aprovechamiento agrícola que pudo existir en siglos anteriores, así como también las distintas edificaciones molinares, ya que las zonas de producción se han visto desplazadas por este mismo hecho. Igualmente, en lo que se refiere al muro defensivo de los siglos XVIIIXIX, tal y como se ha citado con anterioridad, este fue prácticamente desmantelado y enterrado en su totalidad para ser sustituido por una obra de canalización moderna del cauce del río Mapocho que se encarga de contener las crecidas del curso fluvial.

Por otro lado, en Murcia existe una protección específica de distintos elementos asociados con la red hidráulica, así como especialmente con la construcción defensiva indicada, el Malecón. En este sentido, debe tenerse en cuenta que, a nivel nacional, la normativa que rige en materia patrimonial es la Ley 16/1985 de Patrimonio Histórico Español, la cual implanta tres grados de protección que se corresponden con las categorías de Patrimonio Histórico Español, Inventario General de Bienes Muebles y Bien de Interés Cultural (BIC); mientras, a nivel regional, la Ley 4/2007 de 16 de marzo de 2007 sobre el Patrimonio Cultural de la Comunidad Autónoma de la Región de Murcia es la que hace lo propio y establece la tipificación de los mismos de acuerdo a tres categorías: Bien de Interés Cultural (BIC), Bien Catalogado por su Relevancia Cultural (BCRC) y, por último, Bien Inventariado (BI).

A pesar de todo, la actual Huerta de Murcia dista mucho del área agrícola original o de máxima vitalidad histórica, hoy día intensamente transformada y degradada. Sin embargo, todavía se conserva, casi en su totalidad, la importante red hidráulica que irrigaba este espacio, así como importantes monumentos asociados a la misma, aunque esta ha sufrido notables agresiones y modificaciones que han desvirtuado, en parte, la traza y el estado original de esta infraestructura de irrigación y drenaje, como también el paisaje agrícola generado en base a estos aportes hídricos. Asimismo, desafortunadamente, el sistema de riego como conjunto no posee ninguna protección, ni tampoco el paisaje cultural asociado a este, hecho que, sin duda, pone de manifiesto un interés aparentemente insustancial hacia ambos elementos o una incomprensible falta de consideración por las administraciones encargadas de velar por ello.

No obstante, en las últimas décadas, diversos elementos que componen parte de este agregado hidráulico han sido distinguidos con diferentes figuras de protección con distinto grado de salvaguarda (Tabla 1). Con todo, pese a que la consideración como bienes de interés de estos se trata de un hecho de gran relevancia, bien es cierto que supone una desintegración de los diferentes componentes materiales e inmateriales que forman parte de la red hidráulica como conjunto monumental y paisaje cultural.

Tabla 1

Elementos de la Huerta de Murcia con figura de protección decretada por la Dirección General de Bienes Culturales.

\begin{tabular}{|c|c|c|}
\hline Elemento & Año & Figura de protección \\
\hline \multirow[t]{3}{*}{$\begin{array}{l}\text { Noria de Alcantarilla y } \\
\text { acueducto }\end{array}$} & 1982 & $\begin{array}{l}\text { Monumento Histórico } \\
\text { Nacional }\end{array}$ \\
\hline & 1985 & $\begin{array}{l}\text { BIC (sustituía a la } \\
\text { anterior) }\end{array}$ \\
\hline & 2007 & $\begin{array}{l}\text { BIC «Monumento» (susti- } \\
\text { tuía a la anterior) }\end{array}$ \\
\hline $\begin{array}{l}\text { Museo Etnológico de la } \\
\text { Huerta }\end{array}$ & 1982 & $\begin{array}{l}\text { Monumento Histórico } \\
\text { Nacional }\end{array}$ \\
\hline \multirow{2}{*}{$\begin{array}{l}\text { Noria de La Ñora y acue- } \\
\text { ducto }\end{array}$} & 1985 & $\mathrm{BIC}$ \\
\hline & 2007 & $\begin{array}{l}\text { BIC «Monumento» (susti- } \\
\text { tuía a la anterior) }\end{array}$ \\
\hline Azud de la Contraparada & 2002 & $\mathrm{BIC}$ «Monumento» \\
\hline $\begin{array}{l}\text { Consejo de Hombres } \\
\text { Buenos }\end{array}$ & 2008 & $\mathrm{BIC}$ «Inmaterial» \\
\hline $\begin{array}{l}\text { Yacimiento del Arrabal de la } \\
\text { Arrixaca }\end{array}$ & 2011 & BIC «Zona arqueológica» \\
\hline Acueducto de Los Arcos & 2011 & $\mathrm{BIC}$ «Monumento» \\
\hline $\begin{array}{l}\text { Yacimiento de la Senda de } \\
\text { Granada }\end{array}$ & 2015 & $\mathrm{BCRC}$ \\
\hline Puente de Pilas & 2016 & $\mathrm{BCRC}$ \\
\hline $\begin{array}{l}\text { Torre del Molino del Batán } \\
\text { (incluye el molino) }\end{array}$ & 2016 & $\mathrm{BIC}$ «Monumento» \\
\hline Molino Alfatego & 2017 & $\mathrm{BI}$ \\
\hline $\begin{array}{l}\text { Acueducto del Canal de } \\
\text { Torres }\end{array}$ & 2017 & $\mathrm{BI}$ \\
\hline $\begin{array}{l}\text { Molinos de los Álamos y } \\
\text { San Francisco y Azud del } \\
\text { Malecón }\end{array}$ & 2019 & $\mathrm{BCRC}$ \\
\hline Acequias Aljufía y Alquibla & 2020 & $\begin{array}{l}\text { BIC «Lugar de interés } \\
\text { etnográfico» }\end{array}$ \\
\hline
\end{tabular}

Fuente: Elaboración propia. 
Además, otros elementos han sido incluidos en distintos PGOM (Planes Generales de Ordenación Municipal), como es el caso del acueducto sobre la Acequia del Turbedal, la propia Acequia del Turbedal, el Puente del Azarbe del Turbedal o el Puente de las Pilas; así como también ha ocurrido lo mismo en distintos PGOU (Planes Generales de Ordenación Urbana) con el Molino del Amor, la Rueda de Felices, el Puente del Camino Real de Cartagena sobre las Acequias de Barreras y Alguazas, el Molino de Funes o el ya mencionado Molino del Batán. Por otro lado, la Fábrica de la Pólvora fue incluida en el Plan Especial del Centro Histórico Artístico de Murcia. Distinciones e inclusiones de extrema importancia, por cuanto suponen hitos visibles de sensibilización con este patrimonio y su protección frente a las agresiones, además de que, con dicha inclusión, estos recursos patrimoniales legalmente pasan a poseer la categoría de BCRC según la Ley 4/2007, de 16 de marzo, de Patrimonio Cultural de la Comunidad Autónoma de la Región de Murcia.

Por otro lado, en lo que se refiere a la estructura de defensa y dejando a un lado las precitadas Ordenanzas del Malecón, esta afortunadamente posee desde la década de los ochenta del siglo pasado uno de los mayores grados de protección contemplados en la actual legislación española. En este sentido, en 1982 se declara Monumento Histórico-Artístico de carácter nacional según el Real Decreto 1396/1982, amparado en la consideración como tal emitida por la Real Academia de Bellas Artes de San Fernando y la Dirección General del Patrimonio Artístico, Archivos y Museos. Tan solo tres años más tarde, en 1985 y de acuerdo a la Ley 16/1985 de Patrimonio Histórico Español, se le reemplaza esta significación por la de Bien de Interés Cultural (BIC) y décadas más tarde, en 2007, y en base a la Ley 4/2007 de 16 de marzo, de Patrimonio Cultural de la Comunidad Autónoma de la Región de Murcia, se declara BIC con categoría de «Monumento». No obstante, recientemente se ha solicitado la ampliación de protección del bien por la que se pide que también su entorno sea incluido en la misma. Además, debe indicarse la reciente resolución de Decreto n. ${ }^{\circ} 5 / 2020$, de 6 de febrero por el que se declara Bien de Interés Cultural, con categoría de Monumento, el Puente Viejo, en la ciudad de Murcia, un elemento que forma parte de este conjunto defensivo remodelado en el siglo XVIII.

Al margen de lo señalado, en el caso de la Región de Murcia resulta necesario indicar que en las últimas décadas han surgido diferentes asociaciones cuyo propósito principal es la defensa del patrimonio cultural del municipio de Murcia y aledaños. Bienes materiales e inmateriales entre los que se encuentra la propia Huerta de Murcia, en su sentido tangible e intangible más amplio, y la obra de defensa destacada con anterioridad. De acuerdo con esto, deben reseñarse la Asociación para la Conservación de la Huerta de Murcia (HUERMUR), la Asociación Murcia Huerta Viva y la Asociación Histórico Cultural Legado; entidades que son unas férreas guardianas y divulgadoras de este patrimonio. Igualmente, cabe señalar que, con este deseo de protección y divulgación, desde 2013 se creó la Plataforma para la Defensa del Patrimonio Cultural de Murcia, cuyo objetivo es aunar apoyos para realizar actuaciones de denuncia y conservación del patrimonio cultural, natural y paisajístico del municipio de Murcia, reivindicando unas políticas efectivas en su conservación y puesta en valor; todo ello reuniendo a dichas asociaciones $\mathrm{y}$ colectivos con estas inquietudes.

\section{El patrimonio como recurso cultural y turístico}

Del mismo modo que el grado de protección de los elementos reseñados, así como de las infraestructuras secundarias y obras defensivas que dieron lugar a los vitales espacios de huerta, constituye un elemento esencial en la creación de una estimación social hacia estos bienes culturales, el análisis de su puesta en valor en espacios museísticos permite demostrar de forma complementaria el afecto y reconocimiento hacia los mismos (Tabla 2).

En primer lugar, en lo referente a la capital de Chile, existen tres emplazamientos expositivos que abordan en parte de sus discursos alusiones a una o a ambas infraestructuras como elementos patrimoniales de índole cultural e histórica, si bien tan solo dos están operativos ya que el tercero fue clausurado y desde entonces ha cesado su función divulgativa.

La primera instalación a señalar es el Museo Histórico Nacional, espacio cuyos orígenes se remontan a los inicios del siglo XIX, aunque no fue hasta 1911 cuando se promulgó su creación y consolidación mediante decreto. Con todo, este no contó con un emplazamiento adecuado hasta 1982, tras la restauración efectuada entre 1978-1982 del antiguo edificio de la Real Audiencia, donde se ubica en la actualidad con una rica y amplia colección permanente. Un discurso en el que aparecen alusiones a las obras hidráulicas de Santiago (canalización del Mapocho, maqueta de la ciudad donde aparecen varias de sus acequias, la pintura de Rafael Correa de las labores de construcción del Tajamar o varios mascarones de fuentes que antaño estaban emplazadas en la ciudad), además de conservar en el patio la lápida conmemorativa de la construcción de los Tajamares que 

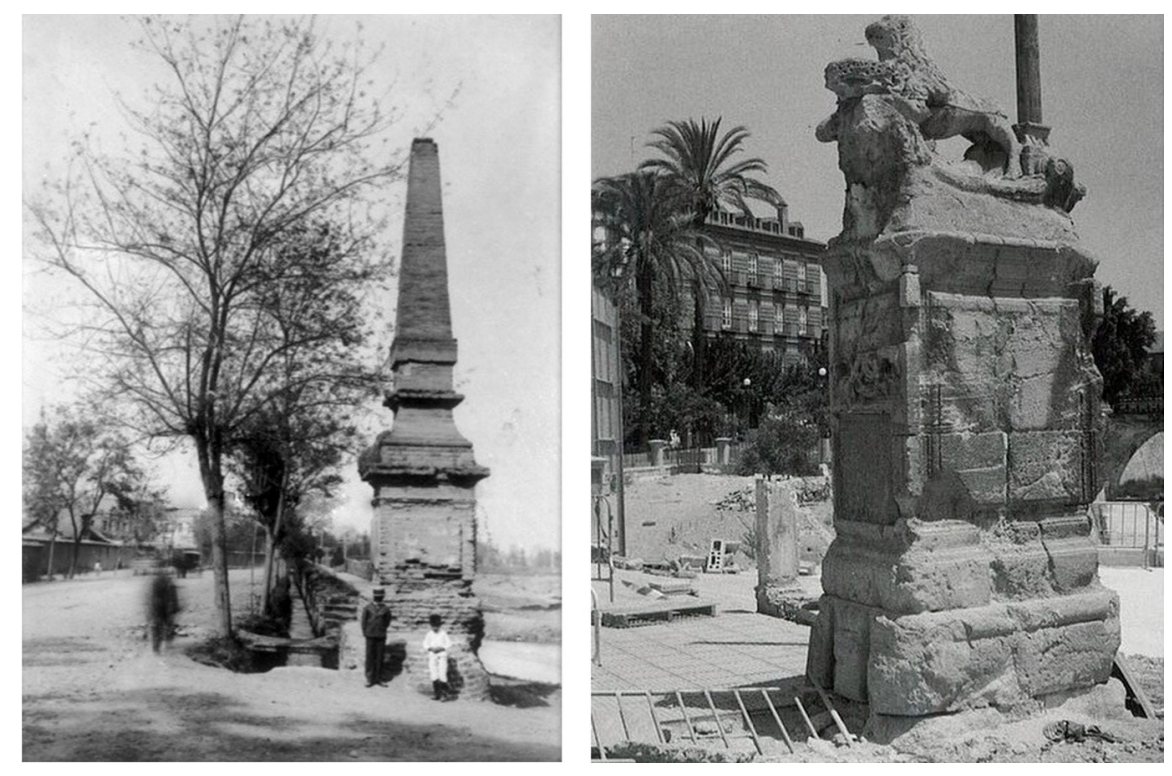

Figura 5. Obelisco conmemorativo de las obras del Tajamar de Santiago de 1792 y obra monumental levantada en Murcia como hito histórico de las obras del Malecón de 1776. Fuente: Pedro Encina y La Opinión de Murcia

se encontraba en el antiguo obelisco levantado junto a la obra defensiva como recordatorio de su ejecución en 1792 y que decía: «D. O. M. REYNANDO CARLOS IIII Y GOBERNANDO ESTE REYNO DON AMBROSIO O'HIGGINS DE VALLENAR MANDÓ HACER ESTOS TAJAMARES. AÑO DE MDCCXCII» (Figura 5).

El segundo centro museográfico de interés es el Museo de Santiago-Casa Colorada; una antigua residencia de estilo colonial edificada entre 1769-1779 para el presidente de la primera junta de gobierno, Mateo de Toro y Zambrano, que fue propiedad de los condes de la Conquista y sus descendientes hasta finales del siglo XX, cuando es adquirida por la Municipalidad. En 1977 fue declarada Monumento Nacional con categoría «Monumento Histórico», y tras su restauración reabre en 1981 como Museo de Santiago. Se inicia desde entonces una amplia labor educativa relacionada con la exhibición de muestras relacionadas con la fundación de Santiago y su desarrollo en el tiempo, entre las que aparecen referencias a las primeras obras hidráulicas emprendidas para aprovechar los recursos de los ríos.

Por último, en 1980 se inauguró el Museo de los Tajamares, dedicado a la divulgación cultural y patrimonial de la obra defensiva. Este se proyectó con motivo de la localización, en 1977 y bajo el Parque Balmaceda de la comuna de Providencia, de importantes restos de la referida infraestructura durante las tareas de construcción de la Línea 1 del Metro de Santiago, hecho que impulsó la creación, por parte de la Municipalidad, de un lugar donde se conservaran dichos hallazgos y se formase un discurso que permitiese a los visitantes conocer la importancia histórica de la obra en la ciudad. Este permaneció abierto hasta 2003, desde entonces se han planteado nuevos proyectos de reapertura con un alcance cultural mayor que el anterior y más dinámico que lo hicieran viable, incluso se traspasó su gestión a la propia municipalidad de la comuna donde se localiza, si bien distintas problemáticas han imposibilitado dicha labor de reacondicionamiento, algunas de ellas recientemente efectuadas (2019) con la intención de rehabilitarlo y que el centro sea gestionado por el Ministerio de Cultura. No obstante, su mera existencia da cuenta de la sensibilidad hacia esta obra.

En segundo lugar, en el extenso territorio del municipio en el que se ubica la urbe de Murcia, existe una importante oferta de museos donde la Huerta -con toda su infraestructuray la obra defensiva del Malecón, constituyen recursos patrimoniales valorados cuya divulgación forma parte del discurso de estos espacios expositivos (Tabla 2). 
Tabla 2

Museos en los que se tiene en consideración en su discurso las obras hidráulicas y/o la obra defensiva.

\begin{tabular}{|c|c|c|c|}
\hline \multicolumn{4}{|c|}{ SANTIAGO } \\
\hline Denominación & Obras hidráulicas & Obra de defensa & Inauguración \\
\hline Museo Histórico Nacional & $x$ & $x$ & 1911 \\
\hline Museo de Los Tajamares & & $x$ & 1980 \\
\hline Museo de Santiago & $x$ & & 1981 \\
\hline \multicolumn{4}{|c|}{ MURCIA } \\
\hline $\begin{array}{l}\text { Museo Etnológico de la Huerta de } \\
\text { Murcia }\end{array}$ & $x$ & & 1968 \\
\hline $\begin{array}{l}\text { Museo Hidráulico "Los Molinos del } \\
\text { Río" }\end{array}$ & $x$ & $x$ & 1989 \\
\hline Museo de la Ciudad & $x$ & $x$ & 1999 \\
\hline Centro de Visitantes de La Luz & $x$ & & 2004 \\
\hline Museo de Santa Clara & $x$ & & 2005 \\
\hline Centro de Visitantes de Monteagudo & $x$ & & 2013 \\
\hline $\begin{array}{l}\text { Centro de Visitantes de La } \\
\text { Contraparada }\end{array}$ & $x$ & & 2019 \\
\hline
\end{tabular}

Fuente: Elaboración propia.

El primer emplazamiento museístico para la divulgación cultural y patrimonial de los valores materiales e inmateriales de la cultura hidráulica y agraria asociada a Murcia y su área huertana circundante se corresponde con el Museo Etnológico de la Huerta de Murcia; un conjunto que, además de contar con la recreación de una cabaña tradicional huertana, está íntimamente ligado a la existencia en sus proximidades de una antigua noria de elevar agua.

El siguiente enclave de interés es el Museo Hidráulico "Los molinos hidráulicos del río", uno de los espacios de mayor interés, por cuanto permite el conocimiento de la propia edificación y la importancia de estas industrias en la sociedad murciana durante siglos.

En tercer espacio, el Museo de la Ciudad, con su contenido arqueológico y etnográfico, permite comprender la evolución histórica, urbana y social de Murcia, a la vez que su relación con el curso fluvial desde el punto de vista de su aprovechamiento a partir de la red hidráulica y la protección histórica contra el mismo, todo ello apoyado con recursos materiales que permiten una visión cultural inmaterial que traspasa lo meramente tangible. En este museo se custodia el león que coronaba la estructura monumental de piedra labrada que conmemoraba la reconstrucción del Malecón a finales del siglo XVIII -como lo haría décadas después el obelisco en Santiagoy cuya lápida en mármol negro decía así: «Se reedificó esta pared y entrada del Malecón, siendo Corregidor y Capitán a guerra de esta ciudad el S. D. Joachín de Preja y Obregón-Chacón Pacheco Merino y Roxas, caballero maestrante del Real de Granada, y Comisarios los señores D. Alexo Díaz Manresa, D. Salvador Vinader Moratón. Año de 1776» (Figura 5).

También el Centro de Visitantes de La Luz en su exposición, que realiza un recorrido por la historia y el patrimonio del valle del río Segura y las pedanías adyacentes desde época íbera hasta las primeras décadas del siglo XX, contiene alusiones a la explotación agrícola de la depresión mediante el aprovechamiento de este curso fluvial.

En el Museo de Santa Clara, el elemento central es la imponente alberca perteneciente a los jardines del antiguo palacio islámico del siglo XIII del Alcázar Seguir, infraestructura que tras su excavación y restauración todavía sigue en funcionamiento gracias a los aportes de la tradicional red de riego y que supone un claro ejemplo del aprovechamiento hídrico desarrollado en esta época extramuros de la ciudad, aunque en este caso con una intención ornamental más que agrícola. 


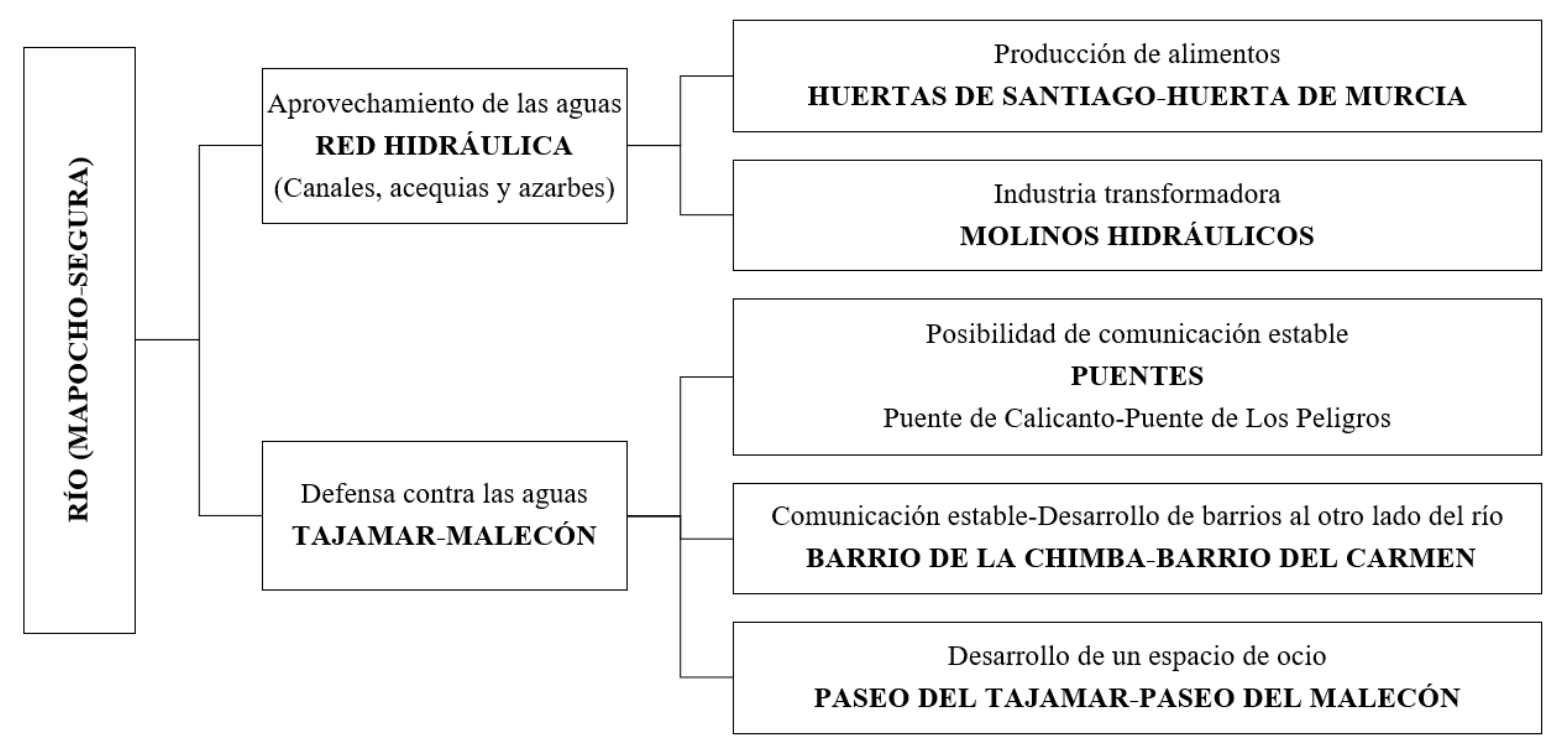

Figura 6. Esquematización de las similitudes entre las ciudades de Santiago y Murcia con respecto al aprovechamiento y defensa de las aguas de sus ríos. Fuente: Elaboración propia.

Igualmente, en el Centro de Visitantes de Monteagudo parte de su discurso, eminentemente arqueológico, se fundamenta en la ocupación del entorno asociado al valle como espacio agrícola destacado y, por supuesto, de abastecimiento a la capital regional, especialmente importante en la época musulmana, tal y como se puede comprobar en la exposición donde la relación de estos con la explotación del curso fluvial representa un hito básico.

Por último, el Centro de Visitantes de La Contraparada constituye la última incorporación al conjunto de museos en los que se pone en valor la temática reseñada, si bien en este caso, como no podía ser de otra forma, el discurso indaga en la amplia cultura hídrica de la ciudad y la relación simbiótica de esta con el río.

\section{Discusión}

Del examen de los resultados expuestos, se deduce un importante número de concordancias entre ambas ciudades en lo que se refiere a la obra asociada al aprovechamiento de los ríos Mapocho y Segura y la forma en que estas se defendieron de los caudales impetuosos de ambos en episodios de crecida (Figura 6). Estas avenidas son acontecidas por regímenes hídricos diferenciados, pero con semejantes efectos catastróficos, tanto sobre la obra humana de sus llanuras aluviales como sobre la población que las habitaba. Unos moradores que en este caso se corresponden con residentes de importantes urbes con un número de vecinos muy considerable, cuyo incremento paulatino se ha mantenido desde su fundación hasta la actualidad a un ritmo extraordinario y, en parte, gracias a dichas construcciones para la explotación de los recursos hídricos en sus huertas y las dirigidas a la contención de las aguas como fundamento esencial de la salvaguarda de sus vidas y actividades.

Resulta indiscutible que los numerosos trabajos de otros autores han manifestado, en mayor o menor grado, esta dicotomía en lo que se refiere a los ríos cuyas aguas hermosean hoy los paisajes urbanos de Santiago y Murcia. No obstante, el paralelismo existente entre ambas metrópolis era una cuestión que había pasado inadvertida para la comunidad científica, no así la importancia del patrimonio hidráulico desarrollado entorno a las corrientes en los dos casos y respecto al que una cantidad significativa de investigadores han formulado excelentes trabajos en los que se analizan los distintos componentes que formaron o forman parte de él. El estudio de cada una de estas aportaciones permite configurar una red de analogías que, si en muchos casos demuestra que no son obras cronológicamente contemporáneas, en otros sí manifiesta esta concordancia temporal, siguiendo, de este modo y en determinadas acciones, unas pautas civiles y arquitectónicas atribuibles a una evolución de las sociedades semejante e influenciada por factores concomitantes. 
En otros casos, como en lo que se refiere a la gobernanza y propiedad de las aguas, las diferencias son importantes. En Santiago han sufrido una profunda modificación desde los momentos previos a la colonización, cuando los pueblos indígenas hacían uso del recurso según normas ancestrales, hasta la actualidad, en la que administración y derecho de aprovechamiento de aguas se rige por el Código de Aguas de 2005, que modifica el de $1981^{11}$ (Ugarte, 2003). En Murcia, la gobernanza que perdura tiene su origen en la época medieval y las aguas del Segura están a disposición de la Junta de Hacendados, conjunto de agricultores que poseen propiedades en este espacio agrícola y, por tanto, derechos de riego; un uso que está estrictamente estipulado, junto con las obligaciones y derechos de los usuarios, en las «Ordenanzas de la Huerta de Murcia» de 1849 (aunque de tradición medieval), siendo el Consejo de Hombres de Buenos (Patrimonio Inmaterial de la Humanidad) el encargado de velar por su cumplimiento y actuar como tribunal de las aguas.

Conforme a esto, no cabe duda de que el agua generó un ingente patrimonio, como se ha justificado en líneas anteriores, al igual que resulta innegable que, en ambos casos, este ha sufrido importantes transformaciones y agresiones por el paso del tiempo y, sobre todo, por la propia voracidad humana y urbana. Del extraordinario conjunto de elementos que existieron tiempo atrás, hoy apenas sobreviven una parte testimonial, mayor en el caso de Murcia donde, obviamente, los procesos urbanizadores han sido menores que en Santiago, capital de una nación, aunque no por ello menos agresivos. De este modo, el irrefrenable tiempo y las acciones humanas desconsideradas, han dado lugar a la desaparición no solo de importantes edificaciones sino también a la pérdida de una cultura del agua intangible parcial o prácticamente olvidada y en grave riesgo de desaparición.

Conforme a esto, tanto en la capital de Chile como en la de la Región de Murcia, la normativa vigente en materia de protección patrimonial se muestra intransigente en cuanto a dichas conductas de destrucción cultural e histórica, así lo demuestra el conjunto de disposiciones legales que velan por su salvaguarda y las distintas figuras de protección estipuladas. Unas figuras con un carácter más globalizador y general en el país sudamericano, tal y como se ha expuesto, y más tediosas y menos prácticas en lo que se refiere a la comunidad española, donde la Dirección General de Bienes Culturales de la Región de Murcia, previo informe administrativo y técnico, es la encargada de discernir qué patrimonio es reconocido, y, por tanto, protegido mediante una designación u otra, $\mathrm{y}$ cuál no; designaciones que además no son respetadas con la rigidez e importancia que debería hacerse ante semejantes elementos monumentales.

Con todo, la falta de sensibilidad y civismo en unas ocasiones y en otras la carencia de cultura o concienciación, son factores de riesgo para la salvaguarda de estos hitos patrimoniales, que no solo están asociados al agua y la cultura hidráulica, si no que forman parte de su historia, explican la evolución mental y social de quienes habitaron estos lugares y son, indiscutiblemente y pese a que parezca lejano, una seña identitaria de la sociedad actual. Una huella pasada que ha influido en los agentes que modelan el paisaje vivido, pero también en la conducta humana como herederos de las obras de unos antepasados que lucharon por el agua y contra el agua y cuyo ingenio y trabajo todavía perduran a pesar de los siglos.

De acuerdo con esto, no debería ser extraño que este patrimonio forme parte del contenido y discurso de los distintos centros expositivos y museos existentes en ambas ciudades, y así es, pero se han registrado importantes diferencias. En Santiago es obvio que existen alusiones al mismo en algunos de ellos, pero tan solo en los principales y de manera sucinta, lo que contrasta con la creación del Museo de los Tajamares, que, si bien no está operativo, demuestra un interés latente, aunque necesitado de un impulso mayor. En lo que respecta a Murcia, como se ha comentado, el número de estos espacios en los que el patrimonio hidráulico tiene cabida es mucho mayor, $\mathrm{y}$, además, existen numerosos museos dedicados en exclusiva a la divulgación cultural en esta línea, algunos de ellos aprovechando edificaciones originales recuperadas asociados al mismo. De este modo, no cabe duda de que en esta ciudad la oferta turístico patrimonial relacionada con el agua es mayor, hecho vinculado a la pervivencia más numerosa de elementos hidráulicos y a una apuesta cultural en este sentido más importante.

A pesar de todo y considerando el marco de estudio, cabe señalar que el rico patrimonio hidráulico, material

\footnotetext{
${ }^{11}$ Un extenso periodo de tiempo en el que, entre otras medidas legislativas, cabe destacar la aplicación de las Leyes de Indias junto con normativa de origen hispánico durante el periodo colonial, el Decreto Supremo de 18 de noviembre de 1819 impulsado por el Gobernador de Chile Bernardo de O'Higgins, el Código Civil de 1855 que dividía las aguas en: comunes a todos los hombres, nacionales de uso público y aguas de dominio privado, y los Códigos de Aguas de 1948 y 1951
} 
e inmaterial, presente en las dos ciudades es, sin duda, un recurso de enorme valor con un gran potencial para ser empleado como atractivo cultural y turístico de múltiples formas posibles tanto físico, vivenciales y virtuales. Un aprovechamiento que ayudaría a fomentar la sensibilización hacia estas obras y constructos sociales históricos y, por tanto, su recuperación, preservación y estima. Solo así, la sociedad será consciente de su importancia y entenderá la relevancia de su salvaguarda, solo así la población y las administraciones entenderán que estos monumentos culturales no son solo un posible recurso económico, sino un recurso social que ayuda a crear cultura y conocimiento y con ello mejores ciudadanos.

\section{Conclusiones}

Santiago y Murcia son dos ciudades condicionadas, desde su origen, por los ríos en cuyas orillas fueron fundadas. De acuerdo con esto, se ha demostrado que, a pesar de las diferencias temporales desde la génesis de cada una de ellas, entre ambas existen importantes similitudes motivadas por su relación con el curso fluvial.

En este sentido, los cursos fluviales propiciaron dos importantes intervenciones humanas en el paisaje: 1 . La creación de un extenso sistema de irrigación que garantizó la explotación agrícola de una importante extensión de terreno y, además, posibilitó la molturación de productos mediante la instalación de molinos hidráulicos sobre las corrientes de estos canales. Y 2. La edificación de un sólido sistema de defensa contra las avenidas fundamentado en el encauzamiento de los dos ríos mediante obras en los tramos que atraviesan las áreas urbanas, lo que dio lugar, asimismo, al crecimiento de sendos barrios en la margen opuesta del río en la que se encontraba el núcleo principal y la edificación de sólidos puentes entre ambas.

Tanto en un caso como en otro, existe una normativa vigente en materia de protección patrimonial de los elementos hidráulicos resultantes de esta interrelación. De este modo, en Chile la ley nacional vela por la salvaguarda de todos aquellos bienes existentes en el país por el simple hecho de tener una relevancia histórica. Por el contrario, para Murcia, generalmente, la normativa vigente hace necesaria la lenta intervención y evaluación de los órganos nacionales y regionales competentes para la designación de una figura de protección que permita la preservación de cualquier elemento.

Por último, se concluye que existe una gran diferencia entre el uso cultural y turístico del patrimonio hidráulico en el caso de Santiago y Murcia, siendo en esta última ciudad mucho más relevantes y numerosas las acciones enfocadas a su divulgación y el equipamiento museístico destinado para tal acción.

\section{Referencias}

Astaburuaga, R. (2004). El agua en las zonas áridas de Chile. Revista ARQ, 57, 68-73. https://dx.doi. org/10.4067/S0717-69962004005700018

Ayarza Elorza, H. (2013). Tajamares del Mapocho. Revista Ingeniería, s.n., 36-37. Recuperado de https:// es.scribd.com/document/401414742/GEO405-504605-Territorio-y-Planeamiento

Calvo García-Tornel, F. (2005). La construcción de los paisajes del miedo: un proyecto de protección contra inundaciones de la ciudad de Murcia en el siglo XVIII. Nimbus: Revista de climatología, meteorología y paisaje, 15-16, 25-42. Recuperado de http://repositorio.ual.es/handle/10835/1387

Castejón Porcel, G. (2015). El paludismo en Fuente Álamo de Murcia en los siglos XVIII y XIX. Investigaciones Geográficas, 64, 87-103. https://doi. org/10.14198/INGEO2015.64.06

Castejón Porcel, G. (2019). El patrimonio hidráulico en Chile: consideración cultural y turística. Cuadernos de Turismo, 1(44), 67-91. https://doi.org/10.6018/ turismo.44.404741

Castejón Porcel, G. \& Canales Martínez, G. (2016). El patrimonio hidráulico de la Región de Murcia y la necesidad de su puesta en valor mediante un Memorial sobre la Cultura del Agua, XV Coloquio Ibérico de Geografía, (pp. 458-567). Recuperado de http://rua.ua.es/dspace/handle/10045/61669

Escalpez Torres, A. (2016). El Malecón de Murcia: historia, análisis de su entorno y propuestas de futuro [Tesis de maestría no publicada]. Universidad de Murcia.

Figueroa Salas, J. (2007). De la forma ruris a la forma urbis. Elementos configuradores del sitio de la ciudad. $A+C, 2,9-25$. Recuperado de https://issuu. com/agueny/docs/amasc_02_2007

Figueroa Salas, J. (2009). Las aguas en la estructura urbana de Santiago de Chile. Hacia un urbanismo de fluidos. Boletín $C F+S$, 42/43, 57-67. Recuperado de http://habitat.aq.upm.es/boletin/n42/aa-jfig.html 
Figueroa Salas, J. (2012). Las trazas de agua y el modelamiento de la planta urbana. En La evolución morfológica de la ciudad de Santiago de Chile. Trayectorias de la Ciudad Moderna, IV Seminario Docomomo. Concepción, Chile, pp. 39-43.

Figueroa Salas, J. (2013). Las trazas del agua y la construcción del paisaje agrícola: las cuencas como factores del diseño urbano. Revista AUS, 213, 15-18. https://doi.org/10.4206/aus.2013.n13-04

Figueroa Salas, J. (2015). Santiago Aquae Urbis: las aguas y la forma de la ciudad. Cuadernos de Arquitectura del agua, 1, 15-28. [sin registro digital]

García Mayor, C. \& Canales Martínez, G. (2018). La Vega Baja del Segura, una Huerta sitiada. La transformación del territorio. Alicante: Universidad de Alicante.

Grindlay, A., Zamorano, M., Rodríguez, M. I., Molero, E. \& Urrea, M. A. (2009). Territorial transformation and water utilization: hydrological planning scenarios in the Segura river basin. WIT Transactions on Ecology and the Environment, 120, 975-984. http:// dx.doi.org/10.2495/SDP090922

Guajardo, A. (2018). Descubriendo el tajamar más oriental de Santiago. Estudio preliminar de una obra de ingeniería hidráulica de fines de la colonia. Revista de Arqueología Histórica Argentina y Latinoamericana, 12, 63-82. Recuperado de http://www.plarci.org/ index.php/RAHAYL/article/view/267

Hidalgo Hermosilla, G. \& Vila Muga, W. (2015). Calles -que fueron- caminos: intensificación de la trama de calles al sur de la alameda en Santiago de Chile hasta fines del siglo XIX. Historia (Santiago), 48(1), 195-244. https://doi.org/10.4067/S071771942015000100006

Lacoste, P. (2018). Molinos harineros en Chile (17001845): implicancias sociales y culturales. América Latina en la historia económica, 25(3), 103-132. http://dx.doi.org/10.18232/alhe.907

López Bermúdez, F. (1978). Inundaciones catastróficas, precipitaciones torrenciales y erosión en la provincia de Murcia. Papeles de Geografia, 8, 4990. Recuperado de https://revistas.um.es/geografia/ article/view/41791
Martí Ciriquián, P. \& Moreno Vicente, E. (2014). La transformación urbana y territorial de la ciudad de Murcia y su entorno (1977-2010). Estudios Geográficos, 75(276), 261-309. https://doi. org/10.3989/estgeogr.201407

Martínez Paz, J., Pellicer-Martínez, F., \& Colino, J. (2014). A probabilistic approach for the socioeconomic assessment of urban river rehabilitation projects. Land use policy, 36, 468-477. https://doi.org/10.1016/j. landusepol.2013.09.023

Peñafiel Ramón, A. (1993). Urbanismo murciano del siglo XVIII: las reformas del Malecón. Imafronte, (8-9), 319-328. Recuperado de https://revistas.um.es/ imafronte/article/view/39721

Puertas, O. L., Henríquez, C. \& Meza, F. J. (2014). Assessing spatial dynamics of urban growth using an integrated land use model. Application in Santiago Metropolitan Area, 2010-2045. Land use policy, 38, 415-425. https://doi.org/10.1016/j. landusepol.2013.11.024

Rosas Vera, J. \& Pérez Villalón, E. (2013). De la ciudad cerrada de los conventos a la ciudad abierta de los espacios públicos: Santiago 1710-1910. Revista de Geografia Norte Grande, 56, 97-119. https://doi. org/10.4067/S0718-34022013000300006

Sahady Villanueva, A., Bravo Sánchez, J., Quilodrán Rubio, C. \& Szmulewicz, P. (2014). Al rescate de los molinos de agua en Chile. En Actas del VI Congreso Latinoamericano de Investigación Turística Neuquén (pp. 1-18). Recuperado de http://170.210.83.98:8080/ jspui/handle/123456789/489

Senent Aparicio, J., Pérez Sánchez, J., Carrillo García, J. \& Soto, J. (2017). Using SWAT and Fuzzy TOPSIS to Assess the Impact of Climate Change in the Headwaters of the Segura River Basin (SE Spain). Water, 9(2), 149. https://doi.org/10.3390/w9020149

Torres Fontes, J. \& Calvo García-Tornel, F. (1975). Inundaciones en Murcia (siglo XV). Papeles del Departamento de Geografía, 6, 29-49. Recuperado de https://revistas.um.es/geografia/article/view/41521

Ugarte Araya, P. (2003). Derecho de Aprovechamiento de Aguas. Análisis histórico, extensión y alcance en la legislación vigente [Memoria de prueba de licenciatura no publicada]. Universidad de Chile. 
Valdés, R., Pizarro, R., García, P., Valdés, J. B., Olivares, C., Vera, M., Balocchi, F., Pérez, F., Vallejos, C., Fuentes, R., Abarza, A. \& Helwig, B. (2014). Water governance in Chile: Availability, management and climate change. Journal of Hydrology, 519, 25382567. https://doi.org/10.1016/j.jhydrol.2014.04.016

Vásquez, A. E. (2016). Infraestructura verde, servicios ecosistémicos y sus aportes para enfrentar el cambio climático en ciudades: el caso del corredor ribereño del río Mapocho en Santiago de Chile. Revista de Geografia Norte Grande, 63, 63-86. https://dx.doi. org/10.4067/S0718-34022016000100005 